\title{
Deep-red and near-infrared xanthene dyes for rapid live cell imaging
}

Guangle Niu, ${ }^{\dagger, *}$ Weimin Liu, ${ }^{* \dagger}$ Bingjiang Zhou, ${ }^{\dagger}$, Hongyan Xiao, ${ }^{\dagger}$ Hongyan Zhang, ${ }^{\dagger}$ Jiasheng Wu, ${ }^{\dagger}$ Jiechao Ge,,$^{\dagger}$ and Pengfei Wang $^{\dagger}$

${ }^{\dagger}$ Key Laboratory of Photochemical Conversion and Optoelectronic Materials and CityU-CAS Joint Laboratory of Functional Materials and Devices, Technical Institute of Physics and Chemistry, Chinese Academy of Sciences, Beijing, 100190, China

*University of Chinese Academy of Sciences, Beijing, 100049, China

${ }^{\S}$ Present Addresses: Key Laboratory of Bioorganic Phosphorus Chemistry \& Chemical Biology (Ministry of Education), Department of Chemistry, Tsinghua University, Beijing, 100084, China

*wmliu@mail.ipc.ac.cn

\section{Table of Contents}

1. Crystallographic data------------------------------------------------------------------------------------------S2

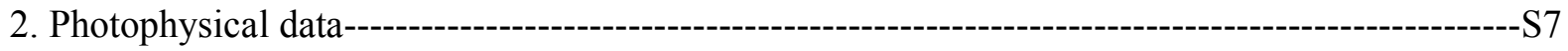

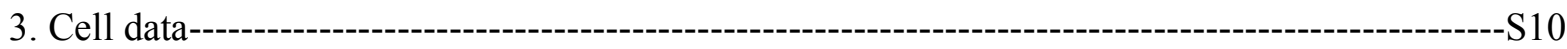

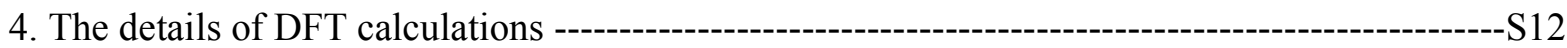

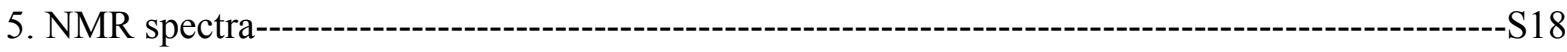

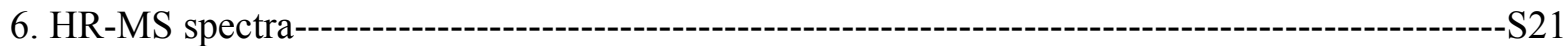




\section{Crystallographic data}

Table S1. Crystal data and structure refinement for H-hNR.

\begin{tabular}{|c|c|c|}
\hline \multirow{2}{*}{$\begin{array}{l}\text { Item analys } \\
\text { Empirical formula }\end{array}$} & \multicolumn{2}{|l|}{ Data } \\
\hline & \multicolumn{2}{|l|}{$\mathrm{C}_{23} \mathrm{H}_{27} \mathrm{ClN}_{2} \mathrm{O}_{5}$} \\
\hline Formula weight & \multicolumn{2}{|l|}{446.91} \\
\hline Temperature & \multicolumn{2}{|l|}{$173.1500 \mathrm{~K}$} \\
\hline Wavelength & \multicolumn{2}{|l|}{$0.71073 \AA$} \\
\hline Crystal system & \multicolumn{2}{|l|}{ Monoclinic } \\
\hline Space group & \multicolumn{2}{|l|}{$\mathrm{P} 121 / \mathrm{n} 1$} \\
\hline \multirow[t]{3}{*}{ Unit cell dimensions } & $\mathrm{a}=7.6833(17) \AA$ & $\mathrm{a}=90^{\circ}$ \\
\hline & $\mathrm{b}=16.259(4) \AA$ & $\mathrm{b}=98.538(3)^{\circ}$. \\
\hline & $c=17.707(4) \AA$ & $\mathrm{g}=90^{\circ}$ \\
\hline Volume & \multicolumn{2}{|l|}{$2187.4(8) \AA^{3}$} \\
\hline $\mathrm{Z}$ & \multicolumn{2}{|l|}{4} \\
\hline Density (calculated) & \multicolumn{2}{|l|}{$1.357 \mathrm{Mg} / \mathrm{m}^{3}$} \\
\hline Absorption coefficient & \multicolumn{2}{|l|}{$0.212 \mathrm{~mm}^{-1}$} \\
\hline $\mathrm{F}(000)$ & \multicolumn{2}{|l|}{944} \\
\hline Crystal size & \multicolumn{2}{|c|}{$0.47 \times 0.37 \times 0.07 \mathrm{~mm}^{3}$} \\
\hline Theta range for data collection & \multicolumn{2}{|l|}{2.759 to $27.481^{\circ}$. } \\
\hline Index ranges & \multicolumn{2}{|c|}{$-9<=\mathrm{h}<=9,-21<=\mathrm{k}<=21,-22<=\mathrm{l}<=22$} \\
\hline Reflections collected & \multicolumn{2}{|l|}{15434} \\
\hline Independent reflections & \multicolumn{2}{|c|}{$4979[\mathrm{R}(\mathrm{int})=0.0369]$} \\
\hline Completeness to theta $=26.000^{\circ}$ & \multicolumn{2}{|l|}{$99.6 \%$} \\
\hline Absorption correction & \multicolumn{2}{|c|}{ Semi-empirical from equivalents } \\
\hline Max. and min. transmission & \multicolumn{2}{|l|}{1.0000 and 0.8023} \\
\hline Refinement method & \multicolumn{2}{|c|}{ Full-matrix least-squares on $\mathrm{F}^{2}$} \\
\hline Data / restraints / parameters & \multicolumn{2}{|l|}{4979 / 0 / 284} \\
\hline Goodness-of-fit on $\mathrm{F}^{2}$ & \multicolumn{2}{|l|}{1.212} \\
\hline Final $\mathrm{R}$ indices $[\mathrm{I}>2 \operatorname{sigma}(\mathrm{I})]$ & \multicolumn{2}{|c|}{$\mathrm{R} 1=0.0720, \mathrm{wR} 2=0.1538$} \\
\hline $\mathrm{R}$ indices (all data) & \multicolumn{2}{|c|}{$\mathrm{R} 1=0.0800, \mathrm{wR} 2=0.1585$} \\
\hline Extinction coefficient & \multicolumn{2}{|l|}{$\mathrm{n} / \mathrm{a}$} \\
\hline Largest diff. peak and hole & \multicolumn{2}{|c|}{0.515 and -0.337 e. $\AA^{-3}$} \\
\hline
\end{tabular}



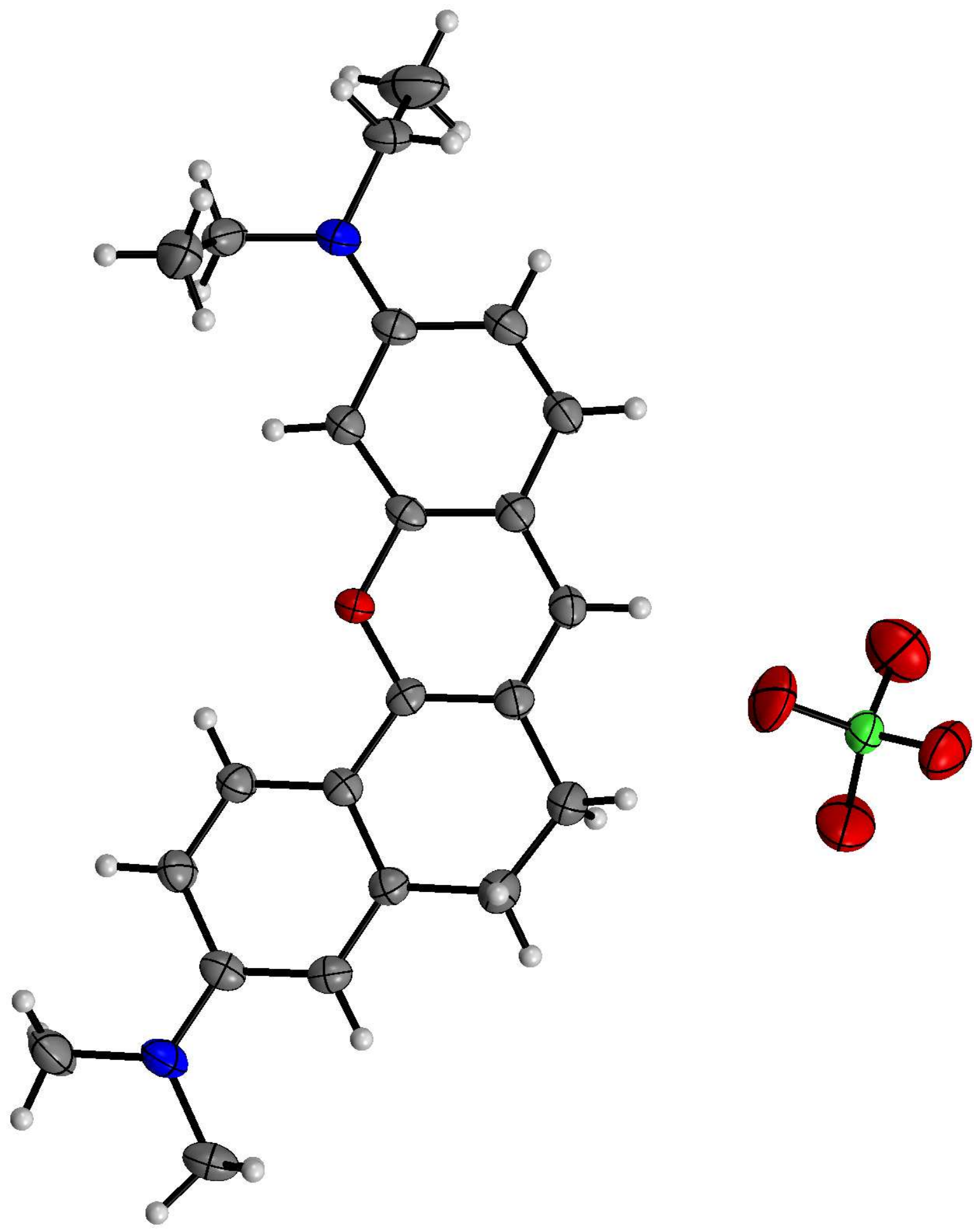

Figure S1. Thermal ellipsoid plots (ORTEP drawing) of H-hNR. (the ellipsoid contour: $50 \%$ probability levels) 
Table S2. Crystal data and structure refinement for TF-hNR.

\begin{tabular}{|c|c|c|}
\hline Item analys & \multicolumn{2}{|l|}{ Data } \\
\hline Empirical formula & \multicolumn{2}{|l|}{$\mathrm{C}_{24} \mathrm{H}_{26} \mathrm{ClF}_{3} \mathrm{~N}_{2} \mathrm{O}_{5}$} \\
\hline Formula weight & \multicolumn{2}{|l|}{514.92} \\
\hline Temperature & \multicolumn{2}{|l|}{$173.1500 \mathrm{~K}$} \\
\hline Wavelength & \multicolumn{2}{|l|}{$0.71073 \AA$} \\
\hline Crystal system & \multicolumn{2}{|l|}{ Monoclinic } \\
\hline Space group & \multicolumn{2}{|l|}{$\mathrm{C} 12 / \mathrm{c} 1$} \\
\hline \multirow[t]{3}{*}{ Unit cell dimensions } & $a=20.165(4) \AA$ & $\mathrm{a}=90^{\circ}$. \\
\hline & $\mathrm{b}=7.1874(14) \AA$ & $\mathrm{b}=104.89(3)^{\circ}$. \\
\hline & $\mathrm{c}=34.207(7) \AA$ & $\mathrm{g}=90^{\circ}$ \\
\hline Volume & \multicolumn{2}{|l|}{$4791.2(18) \AA^{3}$} \\
\hline Z & \multicolumn{2}{|l|}{8} \\
\hline Density (calculated) & \multicolumn{2}{|l|}{$1.428 \mathrm{Mg} / \mathrm{m}^{3}$} \\
\hline Absorption coefficient & \multicolumn{2}{|l|}{$0.221 \mathrm{~mm}^{-1}$} \\
\hline $\mathrm{F}(000)$ & \multicolumn{2}{|l|}{2144} \\
\hline Crystal size & \multicolumn{2}{|c|}{$0.67 \times 0.19 \times 0.18 \mathrm{~mm}^{3}$} \\
\hline Theta range for data collection & \multicolumn{2}{|l|}{2.686 to $27.489^{\circ}$. } \\
\hline Index ranges & \multicolumn{2}{|c|}{$-21<=\mathrm{h}<=26,-9<=\mathrm{k}<=9,-44<=\mathrm{l}<=35$} \\
\hline Reflections collected & \multicolumn{2}{|l|}{15566} \\
\hline Independent reflections & \multicolumn{2}{|c|}{$5441[\mathrm{R}(\mathrm{int})=0.0342]$} \\
\hline Completeness to theta $=26.000^{\circ}$ & \multicolumn{2}{|l|}{$99.3 \%$} \\
\hline Absorption correction & \multicolumn{2}{|c|}{ Semi-empirical from equivalents } \\
\hline Max. and min. transmission & \multicolumn{2}{|l|}{1.0000 and 0.7611} \\
\hline Refinement method & \multicolumn{2}{|c|}{ Full-matrix least-squares on $\mathrm{F}^{2}$} \\
\hline Data / restraints / parameters & \multicolumn{2}{|l|}{$5441 / 16 / 343$} \\
\hline Goodness-of-fit on $\mathrm{F}^{2}$ & \multicolumn{2}{|l|}{1.149} \\
\hline Final $R$ indices $[\mathrm{I}>2 \operatorname{sigma}(\mathrm{I})]$ & \multicolumn{2}{|c|}{$\mathrm{R} 1=0.0751, \mathrm{wR} 2=0.2019$} \\
\hline $\mathrm{R}$ indices (all data) & \multicolumn{2}{|c|}{$\mathrm{R} 1=0.0840, \mathrm{wR} 2=0.2096$} \\
\hline Extinction coefficient & \multicolumn{2}{|l|}{$\mathrm{n} / \mathrm{a}$} \\
\hline Largest diff. peak and hole & \multicolumn{2}{|c|}{0.871 and -0.329 e. $\AA^{-3}$} \\
\hline
\end{tabular}




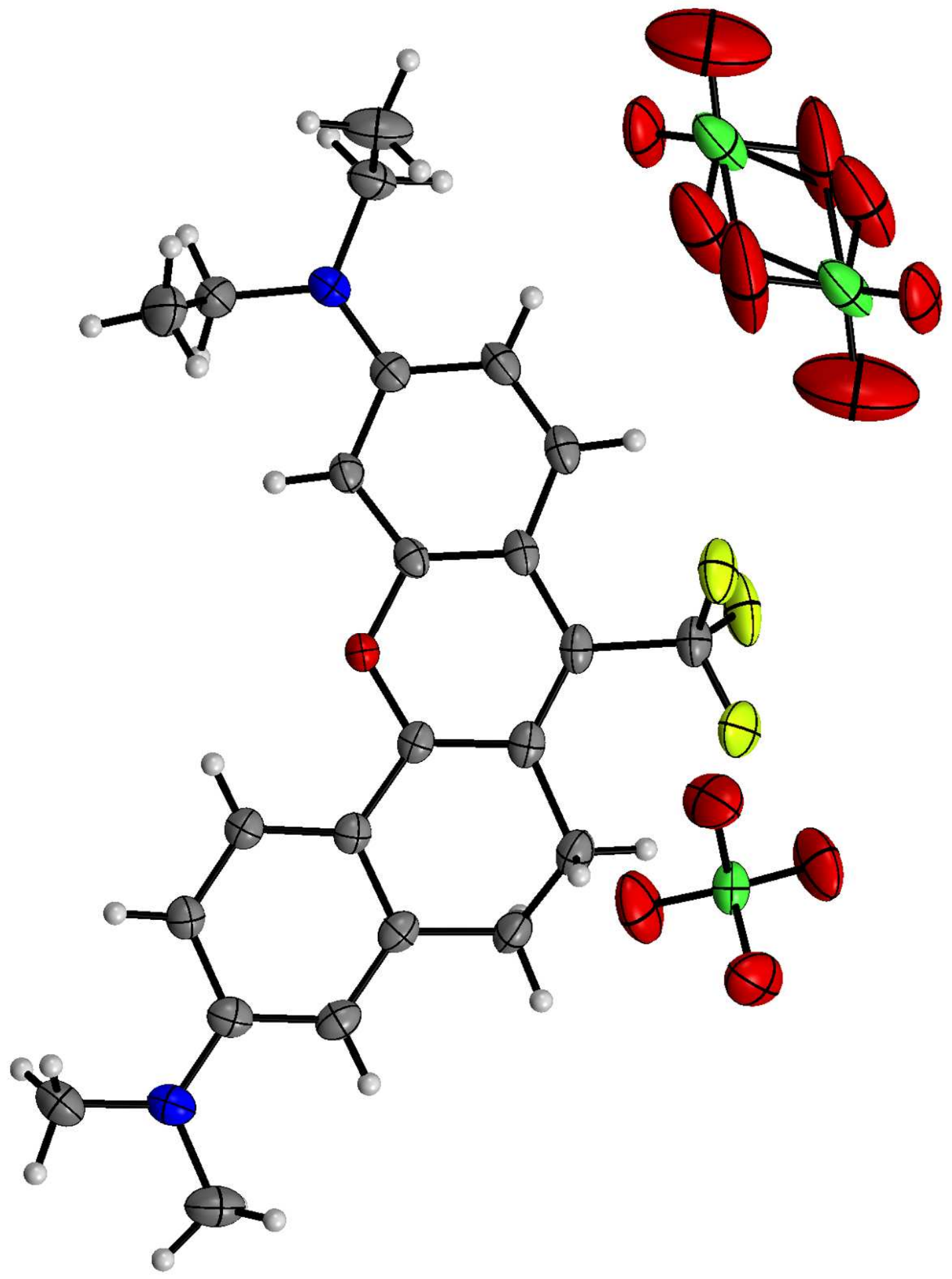

Figure S2. Thermal ellipsoid plots (ORTEP drawing) of TF-hNR. (the ellipsoid contour: $50 \%$ probability levels) 


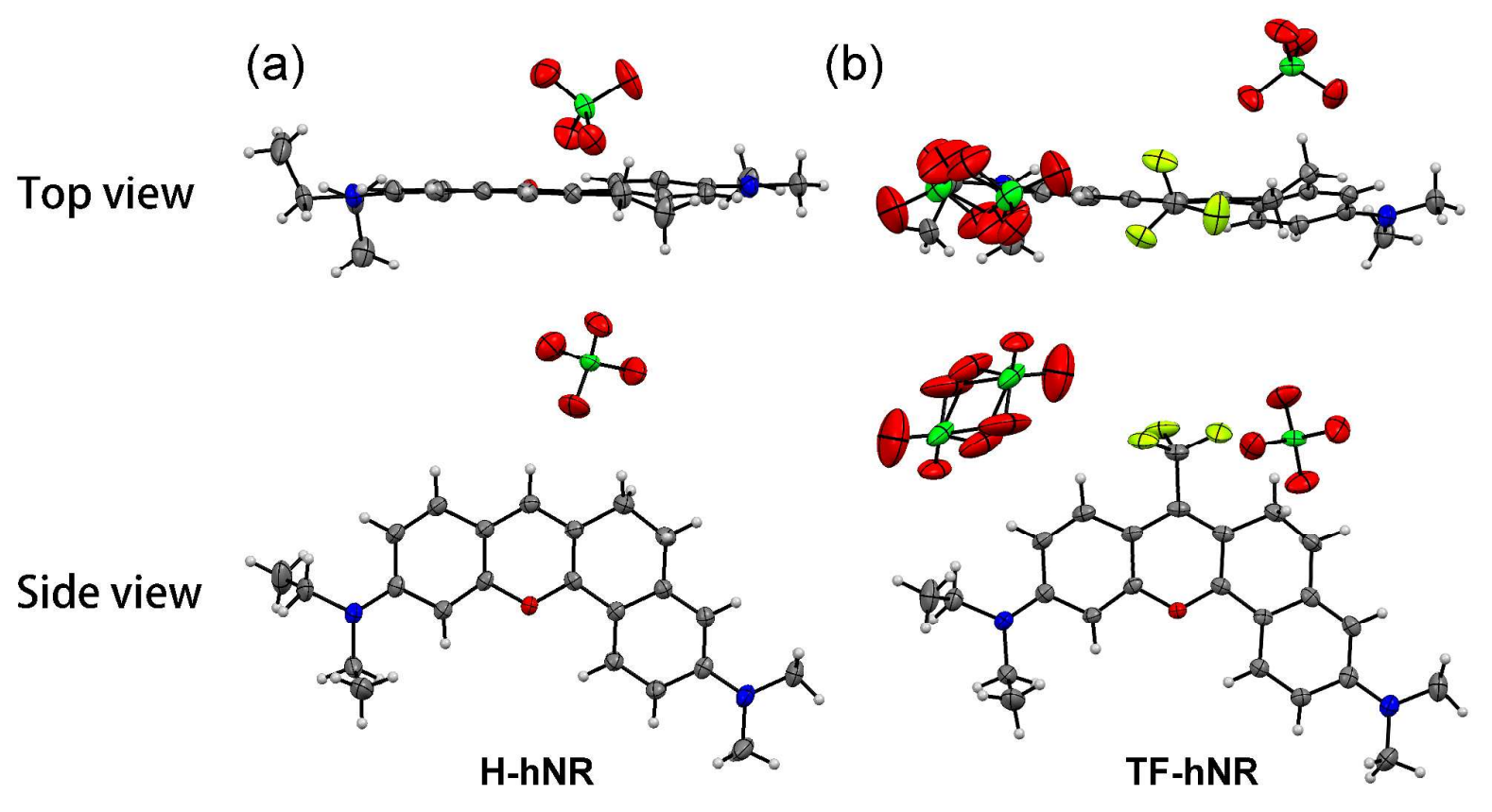

Figure S3. Single-crystal X-ray structures of (a) H-hNR and (b) TF-hNR. C, gray; N, blue; O, red; $\mathrm{F}$, yellow; $\mathrm{Cl}$, green. 


\section{Photophysical data}
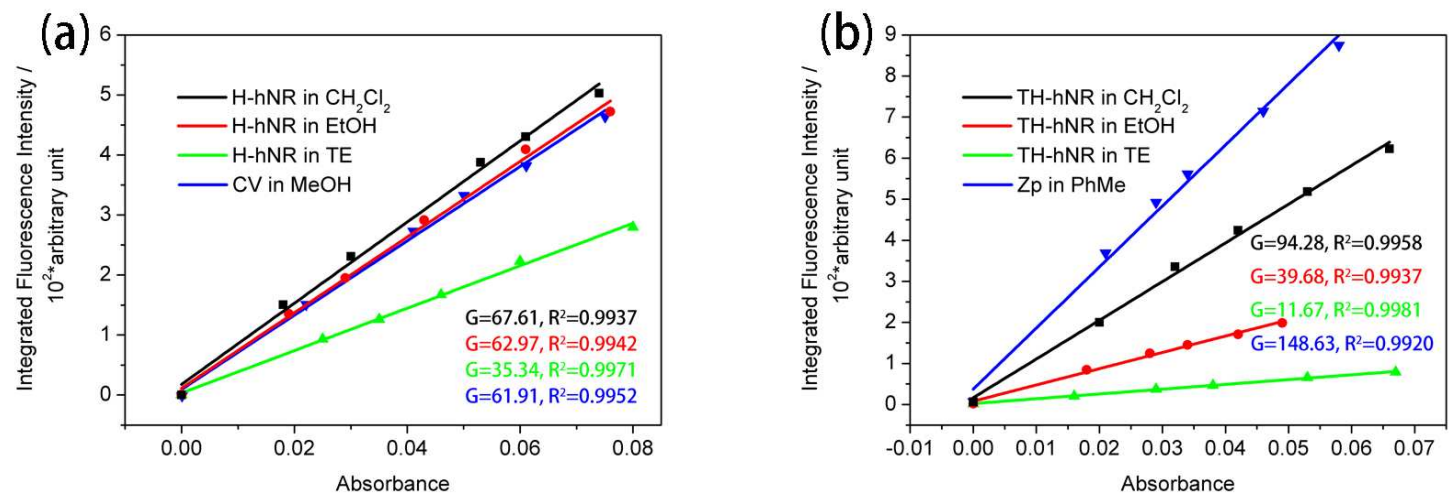

Figure S4. The linear plots for H-hNR, TF-hNR and two standard samples. The data for Zinc phthalocyanine (Zp) was measured in $\mathrm{PhMe}$ (containing 1\% pyridine).

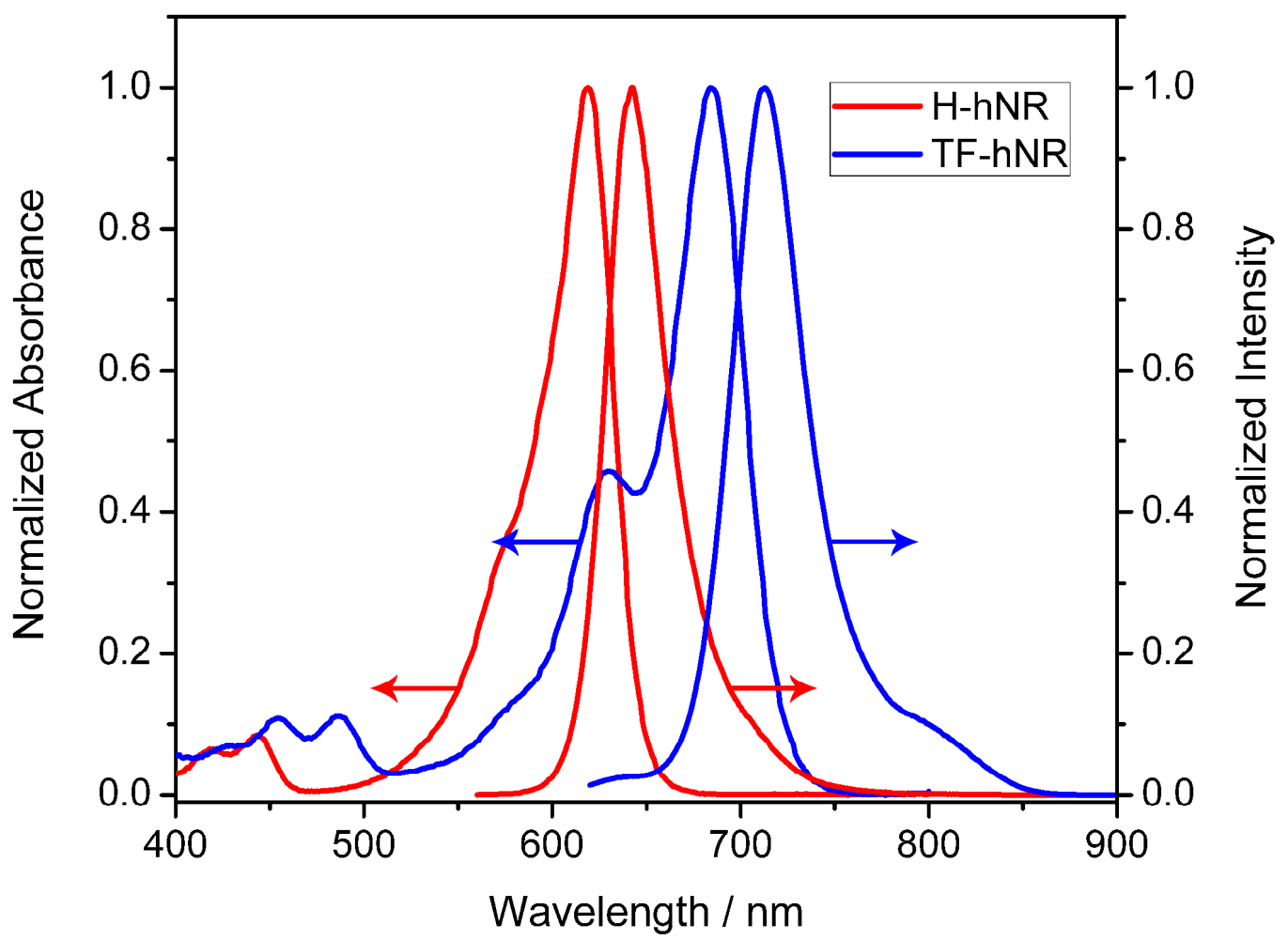

Figure S5. Normalized absorption and fluorescence spectra of $\mathbf{H}-\mathbf{h N R}$ and TF-hNR in $\mathrm{CH}_{2} \mathrm{Cl}_{2}$. 


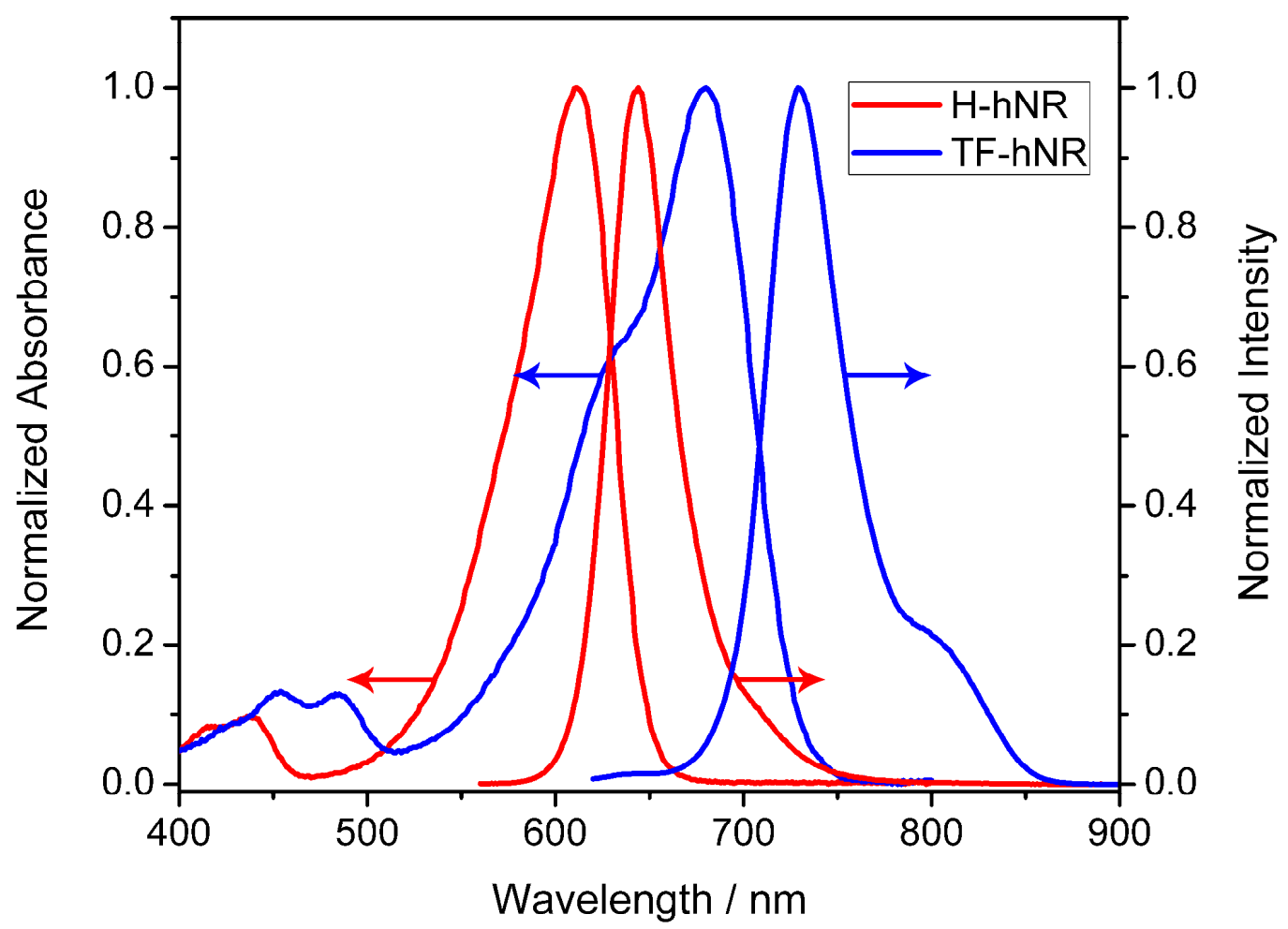

Figure S6. Normalized absorption and fluorescence spectra of $\mathbf{H}-\mathbf{h N R}$ and TF-hNR in EtOH.

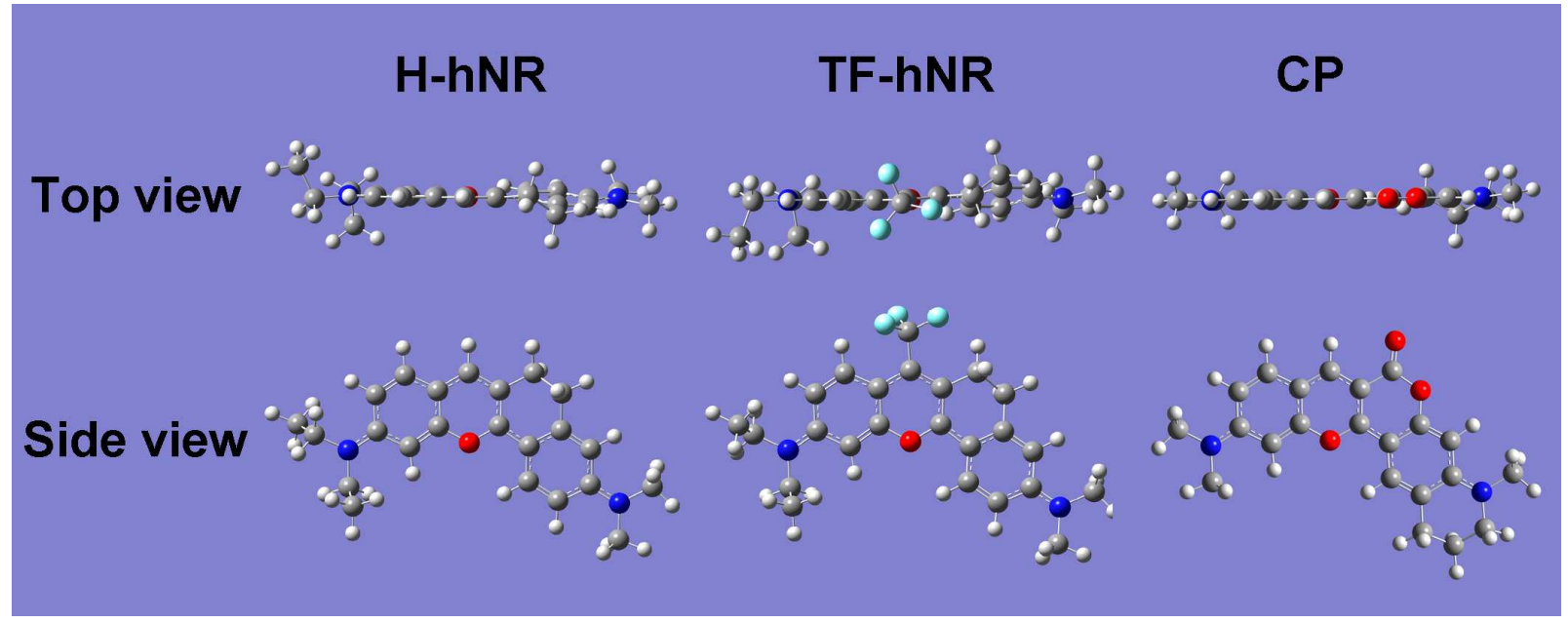

Figure S7. The DFT optimized structures of H-hNR, TF-hNR and CP. 

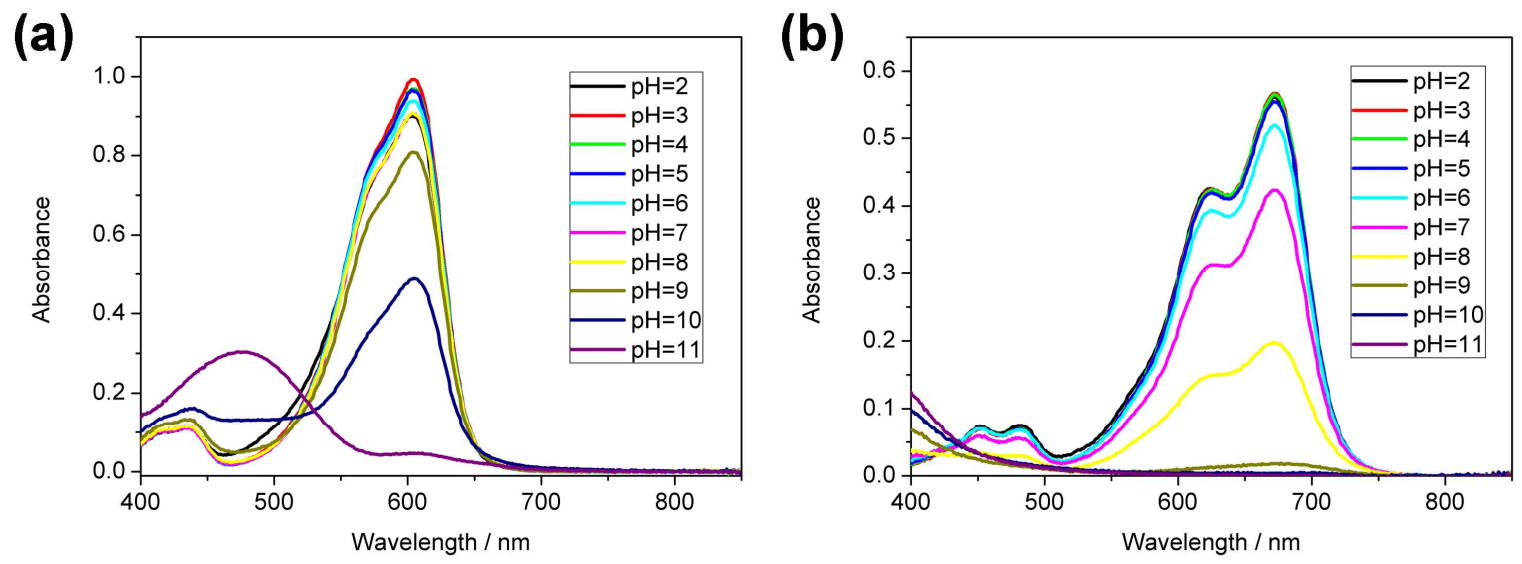

Figure S8. pH-dependence of the absorption of (a) H-hNR and (b) TF-hNR.
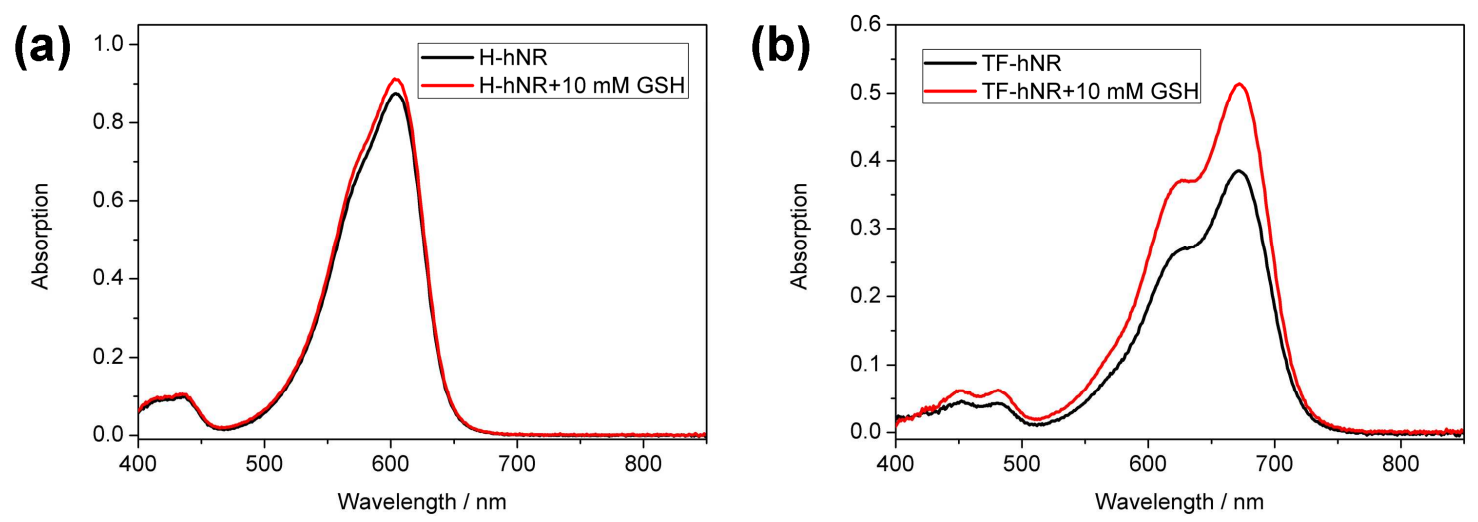

Figure S9. Absorption spectra of (a) H-hNR and (b) TF-hNR in TE buffer (pH 7.4) before (black line) and after (red line) addition of $10 \mathrm{mM} \mathrm{GSH}$. 


\section{Cell data}

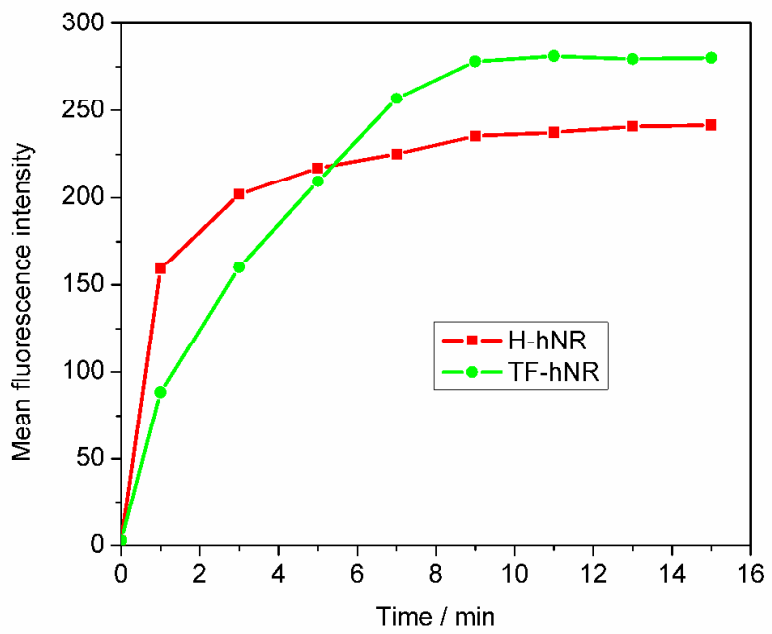

Figure S10. Mean fluorescence intensity of H-hNR and TF-hNR in HeLa cells at different time-points.

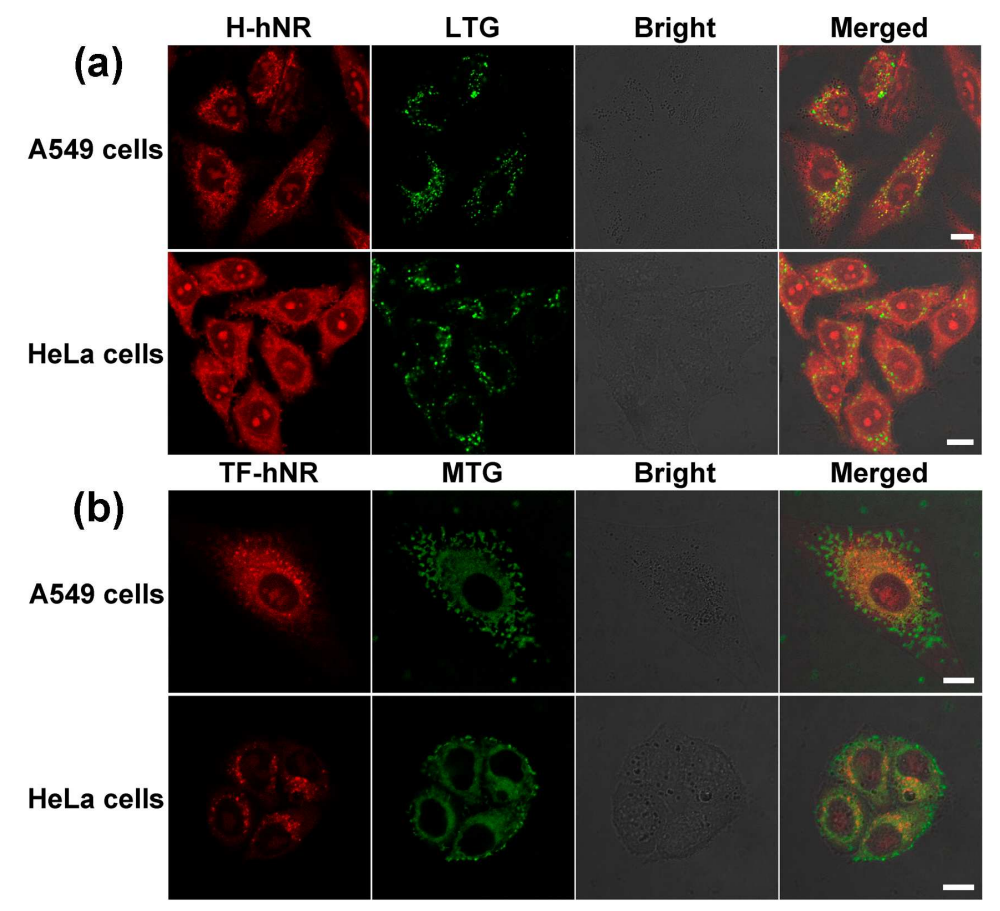

Figure S11. Confocal fluorescence microscopy images of A549 \& HeLa cells (a) stained with LTG (200 nM) and H-hNR (0.8 $\mu \mathrm{M})$ and (b) stained with MTG (100 nM) and TF-hNR $(2 \mu \mathrm{M})$. Scale bar: $10 \mu \mathrm{m}$. 
Table S3 Pearson's coefficient and overlap data

\begin{tabular}{|c|c|c|c|c|}
\hline Cells & Commercial dyes & Data & H-hNR & TF-hNR \\
\hline \multirow{4}{*}{ A549 cells } & \multirow{2}{*}{ MTG $^{[\mathrm{a}]}$} & Pearson's coefficient & 0.87 & 0.59 \\
\cline { 3 - 5 } & & Overlap & 0.89 & 0.65 \\
\cline { 2 - 5 } & \multirow{2}{*}{ LTG $^{[\mathrm{b}]}$} & Pearson's coefficient & 0.48 & 0.86 \\
\cline { 3 - 5 } & & Overlap & 0.52 & 0.87 \\
\hline \multirow{3}{*}{ HeLa cells } & \multirow{2}{*}{ MTG $^{[\mathrm{a}]}$} & Pearson's coefficient & 0.82 & 0.72 \\
\cline { 3 - 5 } & & Overlap & 0.83 & 0.75 \\
\cline { 3 - 5 } & \multirow{2}{*}{ LTG $^{[\mathrm{b}]}$} & Pearson's coefficient & 0.51 & 0.88 \\
\cline { 3 - 5 } & & Overlap & 0.58 & 0.89 \\
\hline
\end{tabular}

${ }^{[\mathrm{a}]} \mathrm{MTG}=$ MitoTracker Green FM. ${ }^{[\mathrm{b}]}$ LTG = LysoTracker Green DND-26.

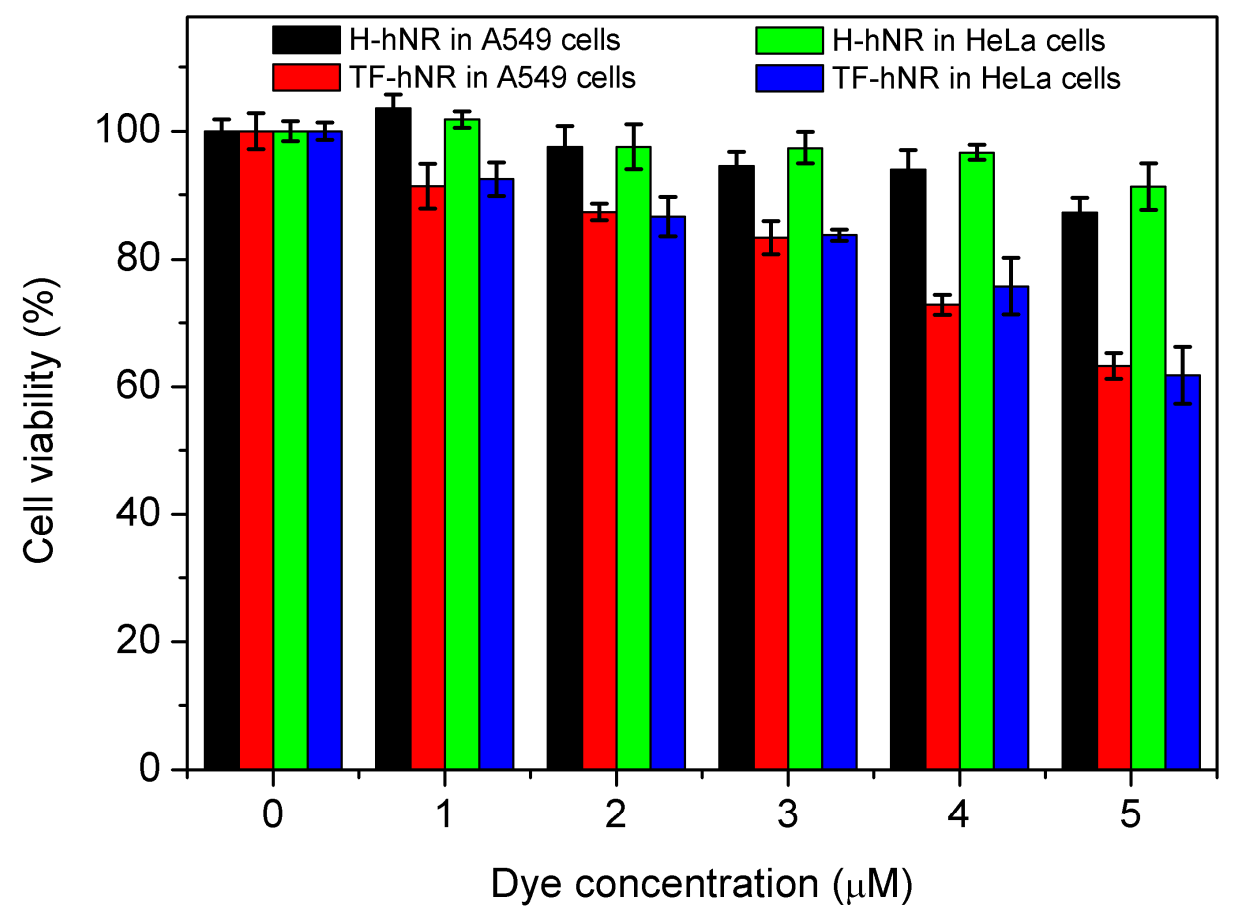

Figure S12. The cytotoxicity of H-hNR and TF-hNR in A549 \& HeLa cells. 


\section{The details of DFT calculations}

Table S4. Atomic coordinates and absolute energy for H-hNR at the B3LYP/6-31G(d) level of theory.

\begin{tabular}{|c|c|c|c|}
\hline Atom & $X$ & $\mathrm{Y}$ & Z \\
\hline $\mathrm{O}$ & -0.229896 & 0.006151 & -0.028437 \\
\hline $\mathrm{N}$ & -4.897571 & -1.001901 & 0.038411 \\
\hline $\mathrm{N}$ & 5.970086 & -1.442994 & -0.118846 \\
\hline $\mathrm{C}$ & -4.374503 & -3.161356 & 1.216319 \\
\hline $\mathrm{H}$ & -3.485145 & -2.762598 & 1.715316 \\
\hline $\mathrm{H}$ & -4.217045 & -4.230988 & 1.037015 \\
\hline $\mathrm{H}$ & -5.221148 & -3.056682 & 1.90369 \\
\hline $\mathrm{C}$ & -4.64913 & -2.44402 & -0.11089 \\
\hline $\mathrm{H}$ & -3.827108 & -2.593774 & -0.8175 \\
\hline $\mathrm{H}$ & -5.536595 & -2.871292 & -0.588309 \\
\hline $\mathrm{C}$ & -7.017665 & -0.290922 & -1.115628 \\
\hline $\mathrm{H}$ & -6.551319 & 0.555988 & -1.629871 \\
\hline $\mathrm{H}$ & -8.066645 & -0.038956 & -0.923093 \\
\hline $\mathrm{H}$ & -6.997272 & -1.150115 & -1.795131 \\
\hline $\mathrm{C}$ & -6.308164 & -0.612421 & 0.204321 \\
\hline $\mathrm{H}$ & -6.371264 & 0.228278 & 0.900903 \\
\hline $\mathrm{H}$ & -6.80854 & -1.449345 & 0.701836 \\
\hline $\mathrm{C}$ & -3.884007 & -0.094151 & 0.032802 \\
\hline $\mathrm{C}$ & -4.151262 & 1.320398 & 0.06345 \\
\hline $\mathrm{H}$ & -5.172931 & 1.676619 & 0.07039 \\
\hline $\mathrm{C}$ & -3.137645 & 2.245649 & 0.058237 \\
\hline $\mathrm{H}$ & -3.377431 & 3.305569 & 0.072463 \\
\hline $\mathrm{C}$ & -1.774297 & 1.851507 & 0.021286 \\
\hline $\mathrm{C}$ & -1.524957 & 0.455772 & -0.010011 \\
\hline $\mathrm{C}$ & -2.52281 & -0.498648 & -0.005691 \\
\hline $\mathrm{H}$ & -2.231971 & -1.540341 & -0.004056 \\
\hline $\mathrm{C}$ & -0.669346 & 2.725402 & -0.000996 \\
\hline $\mathrm{H}$ & -0.84439 & 3.799491 & -0.003206 \\
\hline $\mathrm{C}$ & 0.630404 & 2.243252 & -0.03286 \\
\hline $\mathrm{C}$ & 0.826551 & 0.848506 & -0.032496 \\
\hline $\mathrm{C}$ & 2.116437 & 0.238044 & -0.05152 \\
\hline
\end{tabular}




\begin{tabular}{lccc}
$\mathrm{C}$ & 3.261629 & 1.049298 & 0.202571 \\
$\mathrm{C}$ & 3.059077 & 2.500937 & 0.583221 \\
$\mathrm{H}$ & 2.893712 & 2.556295 & 1.670012 \\
$\mathrm{H}$ & 3.964389 & 3.080049 & 0.374975 \\
$\mathrm{C}$ & 1.85719 & 3.120811 & -0.143048 \\
$\mathrm{H}$ & 2.103826 & 3.252719 & -1.207394 \\
$\mathrm{H}$ & 1.643345 & 4.117391 & 0.257375 \\
$\mathrm{C}$ & 4.522516 & 0.48525 & 0.178612 \\
$\mathrm{H}$ & 5.373988 & 1.123027 & 0.384748 \\
$\mathrm{C}$ & 4.722628 & -0.901446 & -0.090066 \\
$\mathrm{C}$ & 3.562635 & -1.702431 & -0.325838 \\
$\mathrm{H}$ & 3.660913 & -2.760003 & -0.535241 \\
$\mathrm{C}$ & 2.305352 & -1.143848 & -0.300473 \\
$\mathrm{H}$ & 1.44248 & -1.773154 & -0.492447 \\
$\mathrm{C}$ & 6.154839 & -2.87103 & -0.380469 \\
$\mathrm{H}$ & 5.655056 & -3.483563 & 0.379929 \\
$\mathrm{H}$ & 7.219415 & -3.101895 & -0.355706 \\
$\mathrm{H}$ & 5.768647 & -3.148224 & -1.368952 \\
$\mathrm{C}$ & 7.148224 & -0.609778 & 0.121561 \\
$\mathrm{H}$ & 7.221143 & 0.198093 & -0.616713 \\
$\mathrm{H}$ & 8.042945 & -1.226103 & 0.038512 \\
$\mathrm{H}$ & 7.128338 & -0.170087 & 1.126643 \\
\hline $\mathrm{E}(\mathrm{RB} 3 \mathrm{LYP})$ & $=-1077.28556783$ & hartree or $-29314.42695 \mathrm{eV}$ \\
\hline & & & \\
\hline & & & \\
\hline
\end{tabular}


Table S5. Atomic coordinates and absolute energy for TF-hNR at the B3LYP/6-31G(d) level of theory.

\begin{tabular}{|c|c|c|c|}
\hline Atom & $X$ & $\mathrm{Y}$ & Z \\
\hline $\mathrm{F}$ & -2.023746 & 3.592154 & 1.236342 \\
\hline $\mathrm{F}$ & -1.622438 & 4.033751 & -0.865065 \\
\hline $\mathrm{F}$ & -0.086392 & 4.332449 & 0.647454 \\
\hline $\mathrm{O}$ & -0.025272 & -0.616918 & -0.126492 \\
\hline $\mathrm{N}$ & -4.563085 & -2.015408 & -0.502696 \\
\hline $\mathrm{N}$ & 6.200161 & -1.769331 & 0.11774 \\
\hline $\mathrm{C}$ & -3.902722 & -4.10113 & 0.769632 \\
\hline $\mathrm{H}$ & -3.578463 & -5.136069 & 0.611013 \\
\hline $\mathrm{H}$ & -4.811613 & -4.123217 & 1.378805 \\
\hline $\mathrm{H}$ & -3.125419 & -3.584494 & 1.342332 \\
\hline $\mathrm{C}$ & -4.157403 & -3.429047 & -0.585894 \\
\hline $\mathrm{H}$ & -3.271921 & -3.502139 & -1.226535 \\
\hline $\mathrm{H}$ & -4.954786 & -3.95748 & -1.114889 \\
\hline $\mathrm{C}$ & -6.65549 & -1.521178 & 0.833819 \\
\hline $\mathrm{H}$ & -6.193318 & -0.695649 & 1.385073 \\
\hline $\mathrm{H}$ & -6.574527 & -2.424152 & 1.446978 \\
\hline $\mathrm{H}$ & -7.719969 & -1.292203 & 0.709063 \\
\hline $\mathrm{C}$ & -6.008854 & -1.722026 & -0.542391 \\
\hline $\mathrm{H}$ & -6.484906 & -2.56207 & -1.054556 \\
\hline $\mathrm{H}$ & -6.176666 & -0.848736 & -1.180721 \\
\hline $\mathrm{C}$ & -3.638742 & -1.027744 & -0.354124 \\
\hline $\mathrm{C}$ & -4.023744 & 0.355288 & -0.278081 \\
\hline $\mathrm{H}$ & -5.069013 & 0.629983 & -0.320206 \\
\hline $\mathrm{C}$ & -3.103895 & 1.365375 & -0.152585 \\
\hline $\mathrm{H}$ & -3.467076 & 2.383685 & -0.112132 \\
\hline $\mathrm{C}$ & -1.70429 & 1.104926 & -0.087012 \\
\hline $\mathrm{C}$ & -1.345862 & -0.264135 & -0.171054 \\
\hline $\mathrm{C}$ & -2.249042 & -1.302272 & -0.285156 \\
\hline $\mathrm{H}$ & -1.855296 & -2.308669 & -0.320168 \\
\hline $\mathrm{C}$ & -0.656941 & 2.064311 & 0.040657 \\
\hline $\mathrm{C}$ & 0.684862 & 1.680747 & -0.032975 \\
\hline $\mathrm{C}$ & 0.967419 & 0.29137 & -0.092792 \\
\hline $\mathrm{C}$ & 2.281659 & -0.259903 & -0.059957 \\
\hline
\end{tabular}




\begin{tabular}{|c|c|c|c|}
\hline $\mathrm{C}$ & 3.396592 & 0.592635 & -0.300375 \\
\hline $\mathrm{C}$ & 3.112361 & 2.015549 & -0.70431 \\
\hline $\mathrm{H}$ & 2.925971 & 2.040304 & -1.788705 \\
\hline $\mathrm{H}$ & 3.984224 & 2.652445 & -0.524079 \\
\hline $\mathrm{C}$ & 1.896891 & 2.600818 & 0.028142 \\
\hline $\mathrm{H}$ & 2.152499 & 2.784135 & 1.081593 \\
\hline $\mathrm{H}$ & 1.668486 & 3.57121 & -0.409464 \\
\hline $\mathrm{C}$ & 2.523672 & -1.63339 & 0.203511 \\
\hline $\mathrm{H}$ & 1.686178 & -2.298541 & 0.384793 \\
\hline $\mathrm{C}$ & 3.802388 & -2.134278 & 0.263606 \\
\hline $\mathrm{H}$ & 3.942714 & -3.183988 & 0.487825 \\
\hline $\mathrm{C}$ & 4.933669 & -1.284437 & 0.048456 \\
\hline $\mathrm{C}$ & 4.68005 & 0.08922 & -0.244274 \\
\hline $\mathrm{H}$ & 5.505705 & 0.761253 & -0.445811 \\
\hline $\mathrm{C}$ & 6.442329 & -3.185911 & 0.40044 \\
\hline $\mathrm{H}$ & 6.04514 & -3.468601 & 1.382764 \\
\hline $\mathrm{H}$ & 7.516361 & -3.368396 & 0.403223 \\
\hline $\mathrm{H}$ & 5.988868 & -3.827164 & -0.364779 \\
\hline $\mathrm{C}$ & 7.348217 & -0.885322 & -0.092142 \\
\hline $\mathrm{H}$ & 7.344332 & -0.460431 & -1.103491 \\
\hline $\mathrm{H}$ & 8.266068 & -1.458954 & 0.032166 \\
\hline $\mathrm{H}$ & 7.355915 & -0.066431 & 0.636988 \\
\hline $\mathrm{C}$ & -1.083732 & 3.515153 & 0.26502 \\
\hline
\end{tabular}


Table S6. Atomic coordinates and absolute energy for CP at the B3LYP/6-31G(d) level of theory.

\begin{tabular}{|c|c|c|c|}
\hline Atom & $X$ & $\mathrm{Y}$ & Z \\
\hline $\mathrm{O}$ & 1.100107 & -0.269644 & 0.015306 \\
\hline $\mathrm{N}$ & 5.625781 & -1.76418 & 0.027242 \\
\hline $\mathrm{N}$ & -5.297251 & -0.604332 & 0.080519 \\
\hline $\mathrm{C}$ & 5.172958 & -3.156316 & 0.057955 \\
\hline $\mathrm{H}$ & 4.579368 & -3.359074 & 0.957686 \\
\hline $\mathrm{H}$ & 6.041513 & -3.813488 & 0.068247 \\
\hline $\mathrm{C}$ & 7.066466 & -1.488928 & 0.0158 \\
\hline $\mathrm{H}$ & 7.360349 & -0.947413 & -0.890796 \\
\hline $\mathrm{H}$ & 7.606082 & -2.434916 & 0.035289 \\
\hline $\mathrm{C}$ & 4.724958 & -0.751704 & 0.009276 \\
\hline $\mathrm{C}$ & 5.156397 & 0.620478 & -0.021731 \\
\hline $\mathrm{H}$ & 6.213106 & 0.853532 & -0.0313 \\
\hline $\mathrm{C}$ & 4.250739 & 1.649308 & -0.039697 \\
\hline $\mathrm{H}$ & 4.600319 & 2.67776 & -0.063075 \\
\hline $\mathrm{C}$ & 2.849459 & 1.405059 & -0.028252 \\
\hline $\mathrm{C}$ & 2.440007 & 0.041526 & 0.002302 \\
\hline $\mathrm{C}$ & 3.325413 & -1.012601 & 0.020489 \\
\hline $\mathrm{H}$ & 2.931596 & -2.019901 & 0.043518 \\
\hline $\mathrm{C}$ & 1.862847 & 2.400369 & -0.045256 \\
\hline $\mathrm{H}$ & 2.130801 & 3.453365 & -0.069655 \\
\hline $\mathrm{C}$ & 0.516656 & 2.05019 & -0.03068 \\
\hline $\mathrm{C}$ & 0.149203 & 0.689117 & 0.001409 \\
\hline $\mathrm{C}$ & -1.196041 & 0.288322 & 0.021193 \\
\hline $\mathrm{C}$ & -2.177954 & 1.31582 & 0.009024 \\
\hline $\mathrm{C}$ & -0.527591 & 3.089391 & -0.048111 \\
\hline $\mathrm{C}$ & -3.525827 & 1.030211 & 0.025715 \\
\hline $\mathrm{H}$ & -4.218393 & 1.860824 & -0.002243 \\
\hline $\mathrm{C}$ & -3.972523 & -0.317541 & 0.061602 \\
\hline $\mathrm{C}$ & -2.988491 & -1.379883 & 0.085022 \\
\hline $\mathrm{C}$ & -1.655709 & -1.058583 & 0.053763 \\
\hline $\mathrm{H}$ & -0.918465 & -1.855831 & 0.065284 \\
\hline $\mathrm{C}$ & -5.814779 & -1.984488 & 0.027433 \\
\hline $\mathrm{C}$ & -6.295172 & 0.459818 & 0.195841 \\
\hline
\end{tabular}




\begin{tabular}{lccc}
$\mathrm{H}$ & -6.079529 & 1.109242 & 1.051016 \\
$\mathrm{H}$ & -7.274106 & 0.005036 & 0.352777 \\
$\mathrm{H}$ & -6.338236 & 1.06982 & -0.715304 \\
$\mathrm{H}$ & 4.572348 & -3.396236 & -0.827878 \\
$\mathrm{H}$ & 7.366638 & -0.907099 & 0.894907 \\
$\mathrm{O}$ & -1.837194 & 2.641472 & -0.02746 \\
$\mathrm{O}$ & -0.322075 & 4.276428 & -0.078289 \\
$\mathrm{C}$ & -3.460114 & -2.813458 & 0.156701 \\
$\mathrm{C}$ & -4.803217 & -2.960262 & -0.562513 \\
$\mathrm{H}$ & -2.706538 & -3.47952 & -0.277204 \\
$\mathrm{H}$ & -3.577767 & -3.114174 & 1.208722 \\
$\mathrm{H}$ & -6.724911 & -1.968855 & -0.580891 \\
$\mathrm{H}$ & -6.104666 & -2.294378 & 1.042558 \\
$\mathrm{H}$ & -5.19361 & -3.978298 & -0.461557 \\
$\mathrm{H}$ & -4.678414 & -2.761931 & -1.634595 \\
\hline $\mathrm{E}(\mathrm{RB} 3 \mathrm{LYP})=-1186.01813513$ hartree or $-32273.19016 \mathrm{eV}$ \\
\hline
\end{tabular}




\section{NMR spectra}

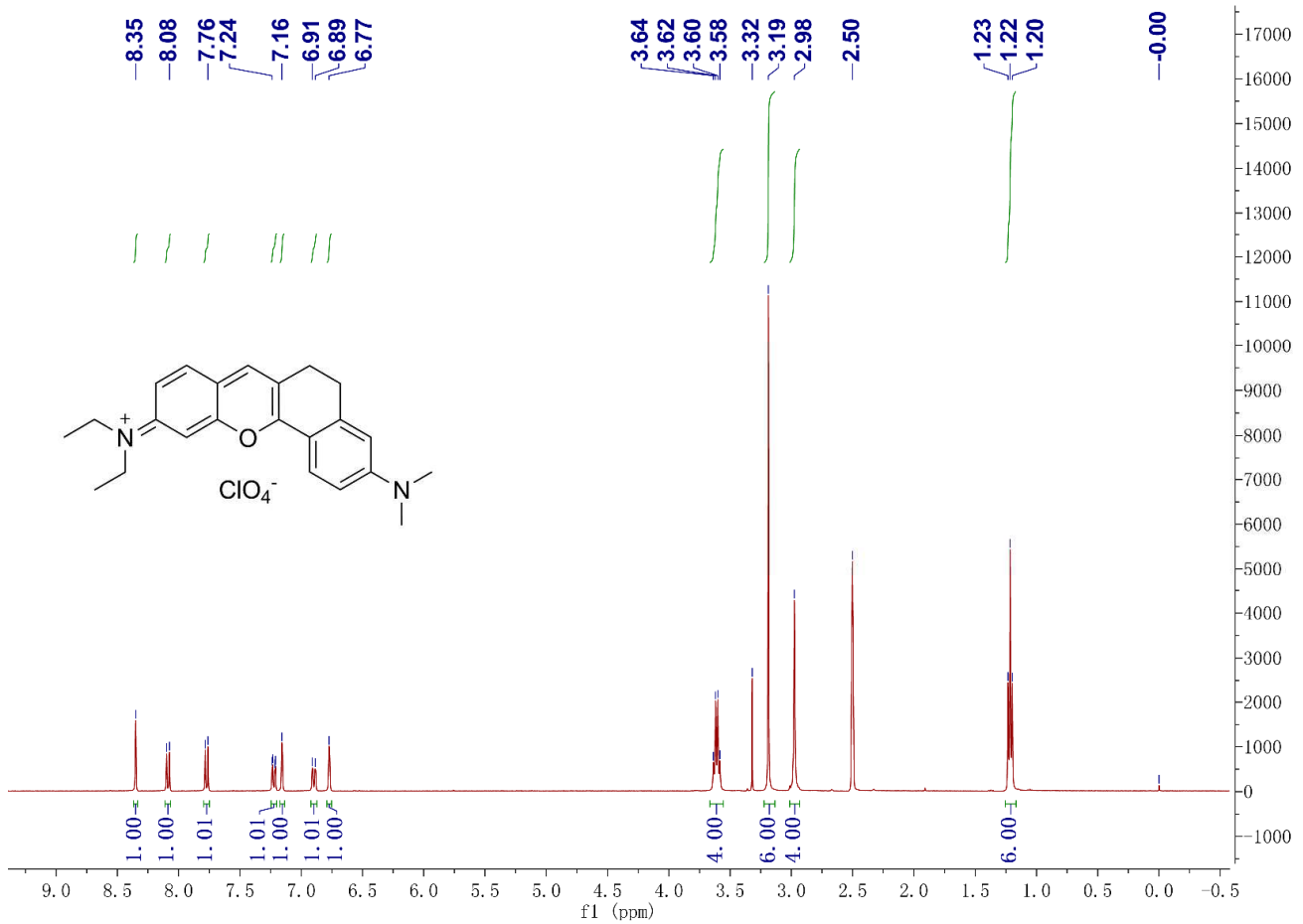

Figure S13. ${ }^{1} \mathrm{H}$ NMR (400 MHz, DMSO-d $\left.\mathrm{d}_{6}\right)$ : H-hNR.

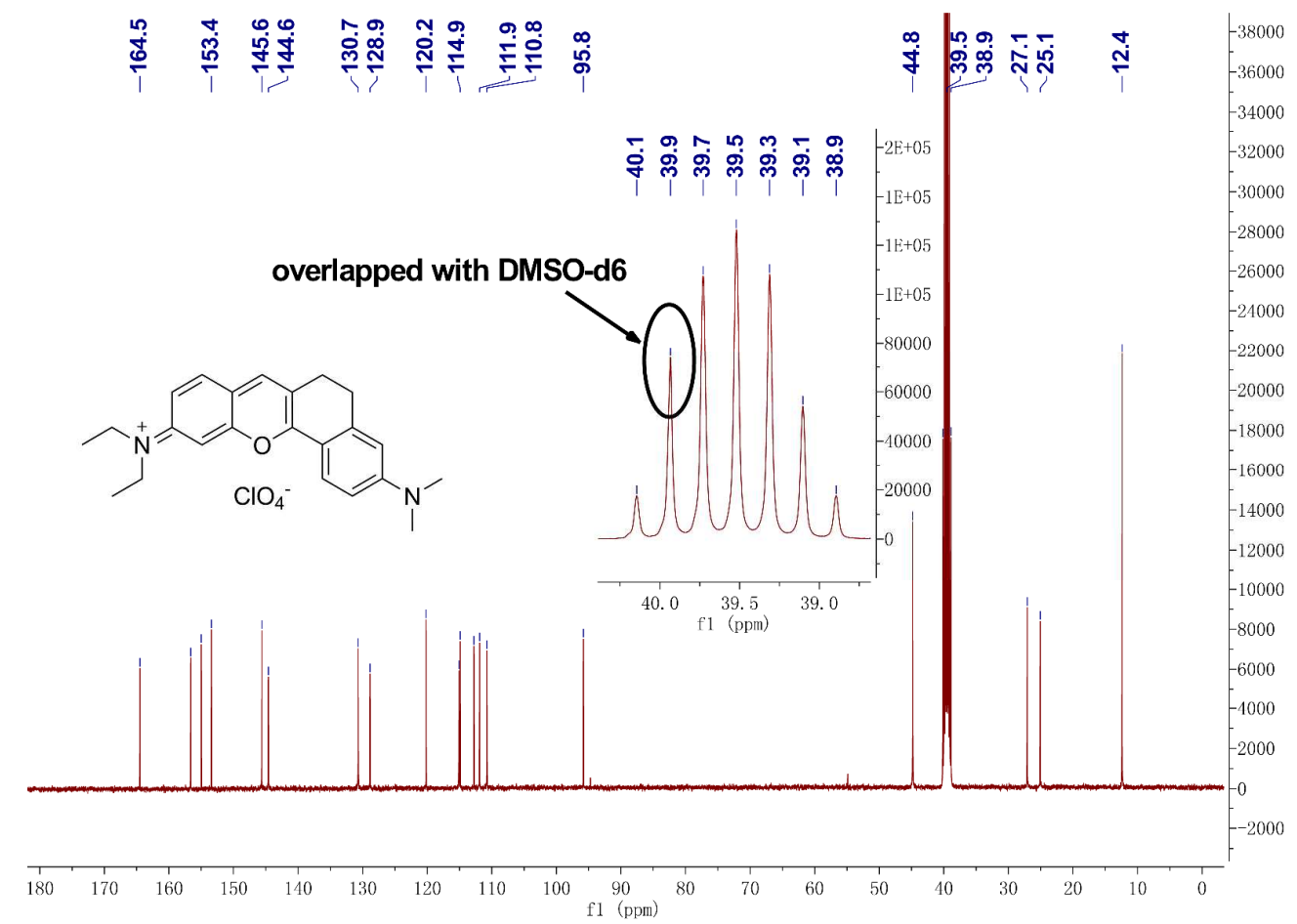

Figure S14. ${ }^{13} \mathrm{C}$ NMR (100 MHz, DMSO-d 6 ): H-hNR. 


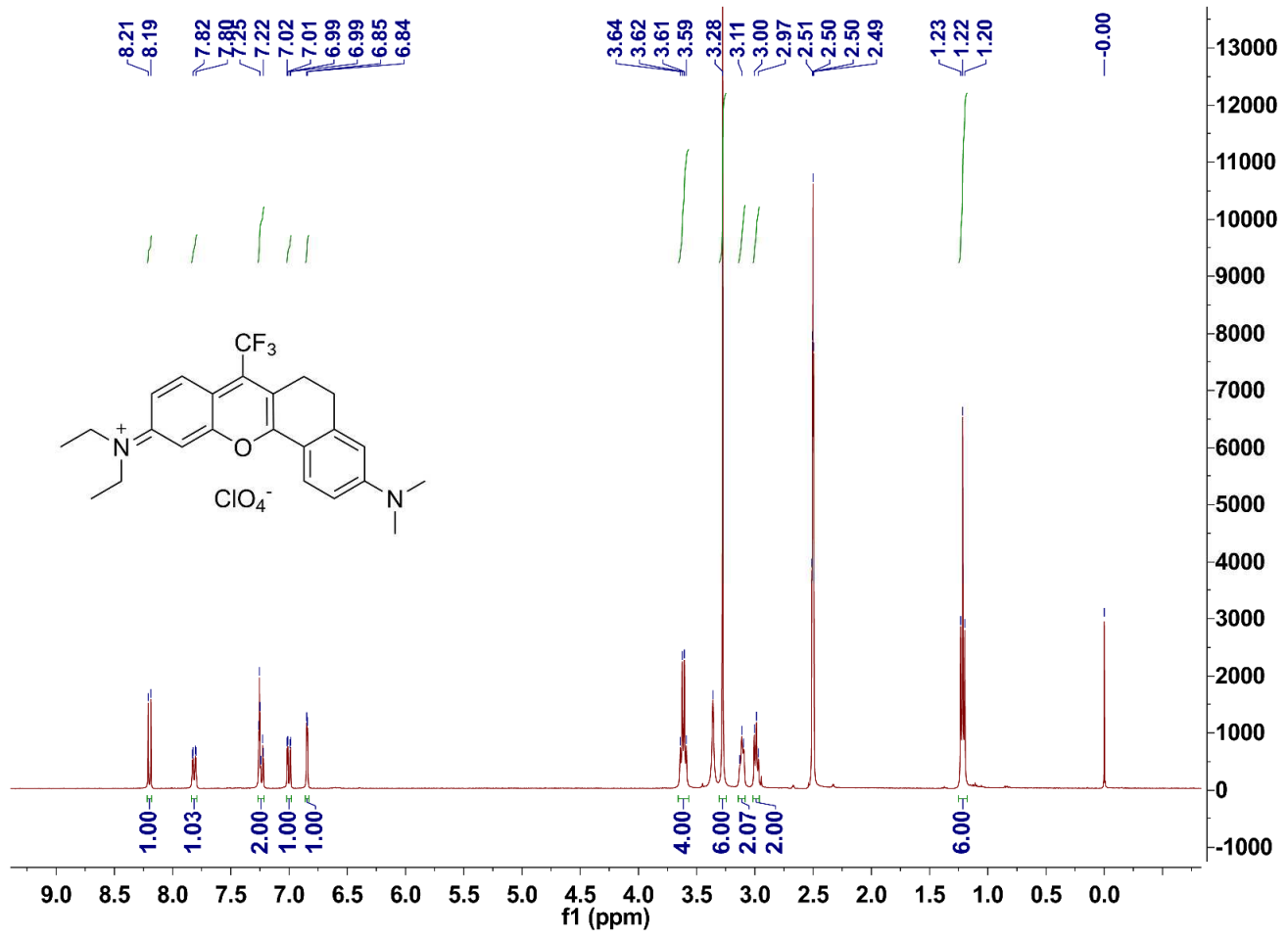

Figure S15. ${ }^{1} \mathrm{H}$ NMR (400 MHz, DMSO-d 6 ): TF-hNR.

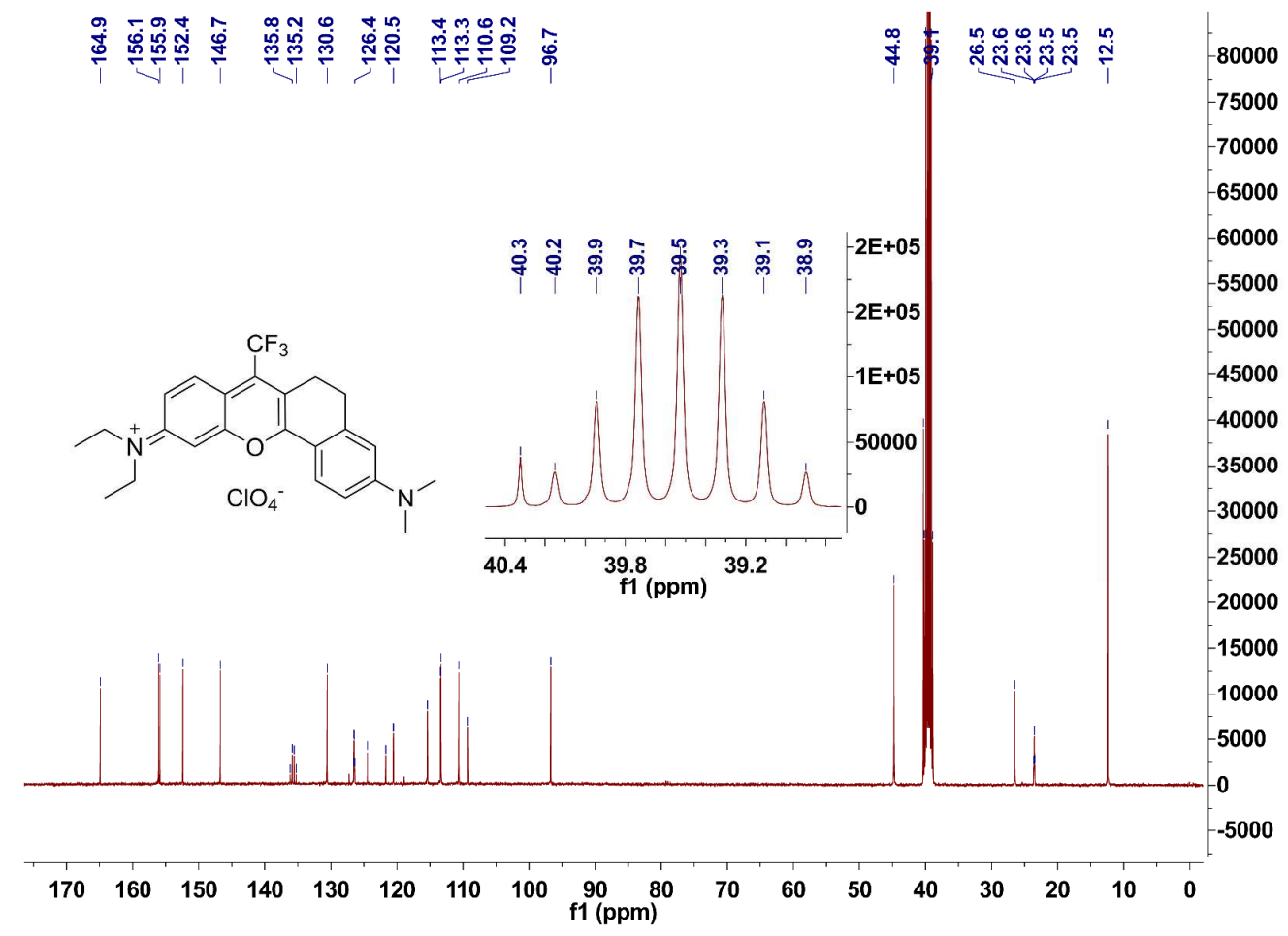

Figure S16. ${ }^{13} \mathrm{C}$ NMR $\left(100 \mathrm{MHz}, \mathrm{DMSO}-\mathrm{d}_{6}\right)$ : TF-hNR. 


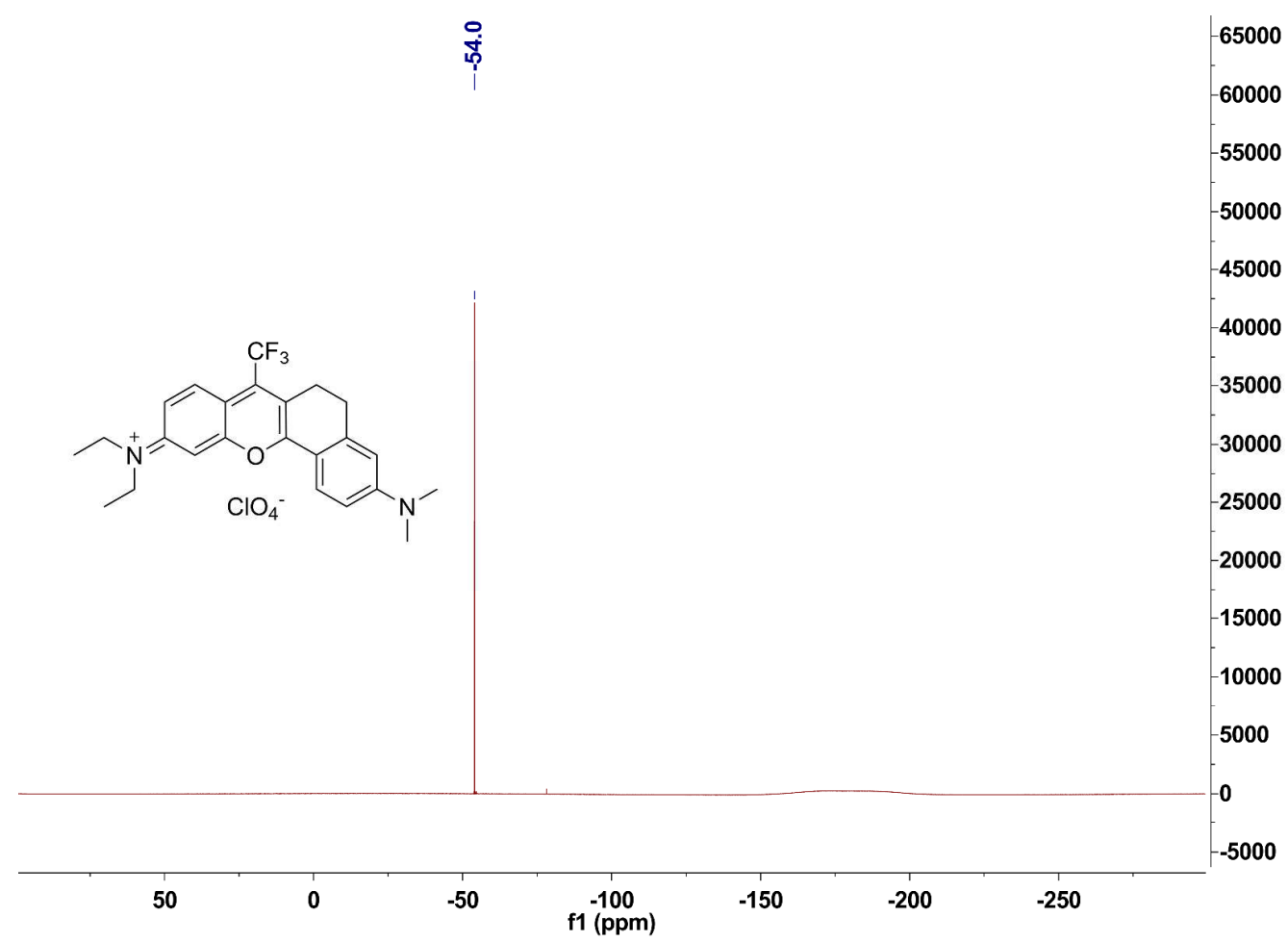

Figure S17. ${ }^{19} \mathrm{~F}$ NMR (376 MHz, DMSO-d 6 ): TF-hNR. 


\section{HR-MS spectra}

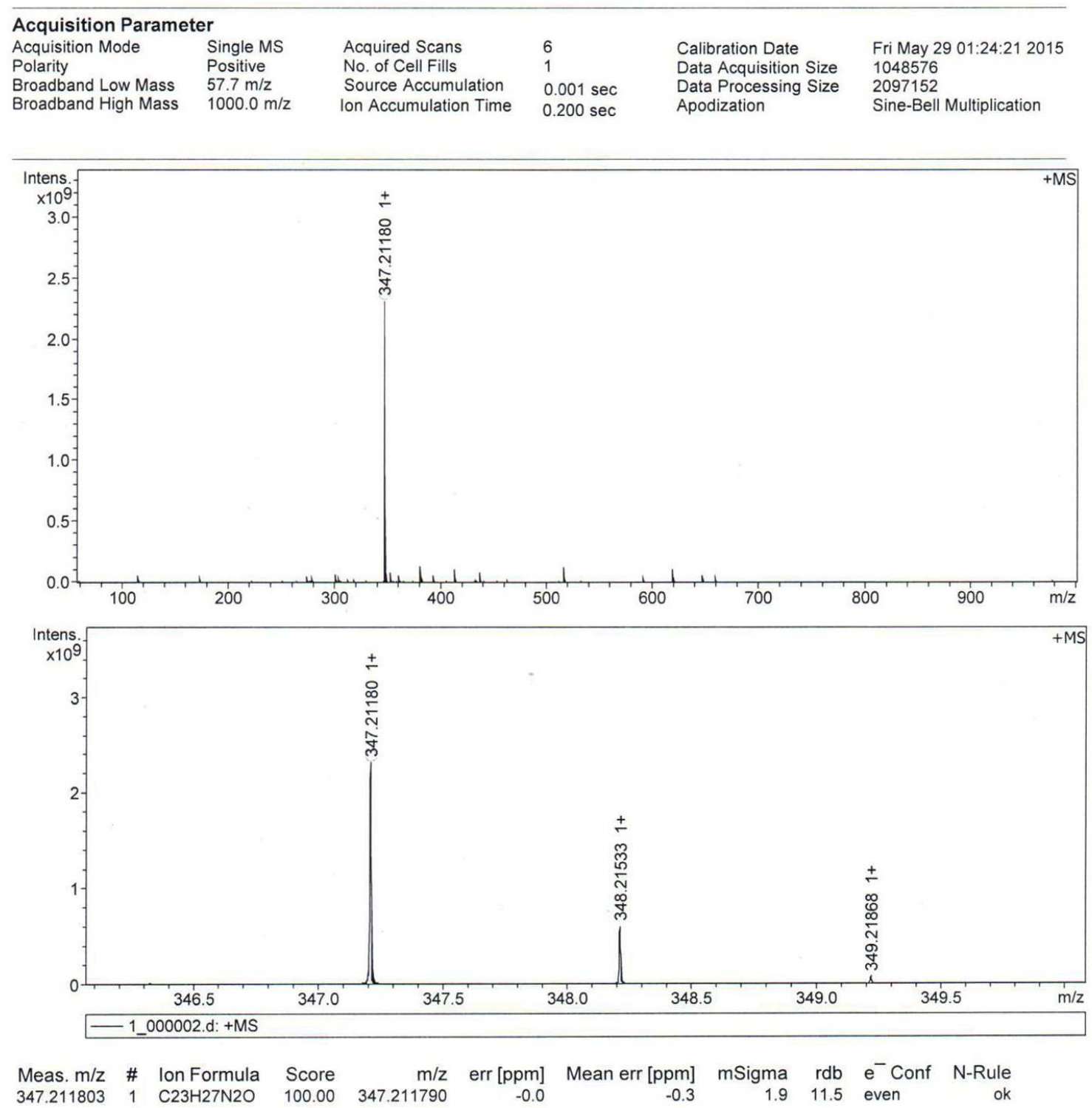

Figure S18. ESI-HRMS spectra of H-hNR. 


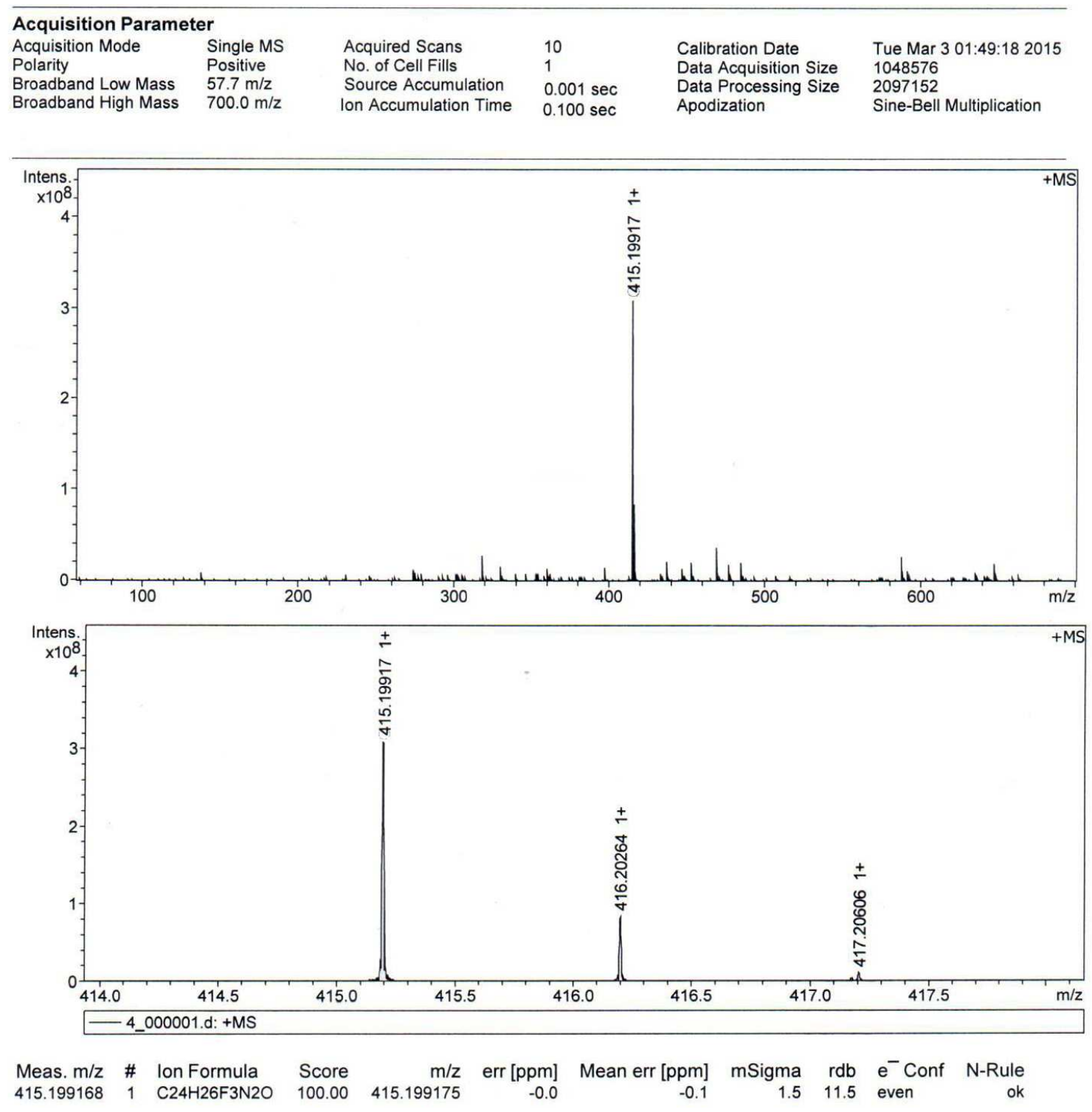

Figure S19. ESI-HRMS spectra of TF-hNR. 